\title{
Spatial and temporal patterns of acidity and heavy metals in predicting the potential for ecological impact on the Le An river polluted by acid mine drainage
}

\author{
M. He, Z. Wang* , H. Tang \\ SKLEAC, Research Center for Eco-Environmental Sciences, PO Box 2871, Beijing 100085, Peoples' Republic of China
}

Received 30 May 1997; accepted 24 July 1997

\begin{abstract}
Integration and comparison of metal contamination from acid mine drainage and an assessment of the potential for ecological impact was conducted in the aquatic ecosystems of the Le An river. The results indicated low acidity, high levels of suspended solids containing a high content of copper in river water and sediment in the upstream region of the Le An river due to the pollution from the Dexing copper mine, and high concentrations of zinc and copper in surface water and sediments, high release potential and ready bioavailability of heavy metals in sediments downstream (after site A07) due to the pollution from the Jishui river. The pollution from acid mine drainage in the Le An river potentially effects an ecological impact on the aquatic ecosystem, mainly between sites A04 and A08. The management strategy should, therefore be mainly applied to acid mine drainage from the Dexing copper mine and heavy metal discharges from the Jishui river. (c) 1997 Elsevier Science B.V.
\end{abstract}

Keywords: Acid mine drainage; River; Heavy metal; Distribution; Ecological impacts

\section{Introduction}

A large quantity of acid mine drainage is produced due to the weathering of waste mines of metal sulfides, and is one of the major causes of

\footnotetext{
*Corresponding author. e-mail: wangzj@mail.rcees.ac.cn.
}

pollution in the surrounding environment. There is voluminous literature on the topic of pollution by acid mine drainage (Boult et al., 1994; Cabrera et al., 1984; Chapman et al., 1983; Foster et al., 1978).

China is rich in non-ferrous metal sulfide resources. The Dexing copper mine, located near the Gukou site in the upstream section of the Le 
An river (279 km long), is the largest open-cast copper mine in Jiangxi Province, China. Its ore production in recent times is over 60000 tons/day and will expand to 100000 tons / day or more by the end of this century. The Dawu river, running through the Dexing copper mine, receives waste discharges from the mine and flows into the Le An river at Gukou (site A04). A small tributary, the Jishui river (J.R., $39 \mathrm{~km}$ long) is a further metal-polluted river along several small sulfide mines and smelters; it runs into the Le An river at Daicun (site A07) and finally flows into Poyang Lake, the largest fresh-water lake in China. Consequently, a large amount of various pollutants, mainly heavy metals, have been discharged into the Le An river where they cause significant ecological impact.

During 1987 and 1995, the Cooperative Ecological Research Project (CERP) was launched within the international Man and Biosphere (MAB) program, supported by the Federal Ministry for Re- search and Technology (BMBF), Germany. The 'Ecological Effects of Heavy-metal Pollution in the Dexing Copper Mine Region' program, one of eight CERP sub-projects, was carried out to assess the impact of the mining operation (Tang et al., 1994; Muller and Tang, 1996).

A previous study of metal pollution by acid mine drainage in the Le An river was concerned mainly with the distribution (Yahya and Song, 1994; Ramezani, 1996; Lin et al., 1992; Lin and $\mathrm{Li}, 1992$ ), absorption (Du et al., 1994), transport (Lin and Li, 1994), speciation (Mao, 1996; Mao et al., 1992), toxicity (Wang et al., 1994; Wang and Tang, 1994), as well as ecological investigation (Xu et al., 1994; Zhu et al., 1994). No attention has been paid to the integration and comparison of the physico-chemical data and the assessment of the potential for ecological effect.

The major objective of this paper, by integrating the data obtained from the CERP program and using the approach of principal components

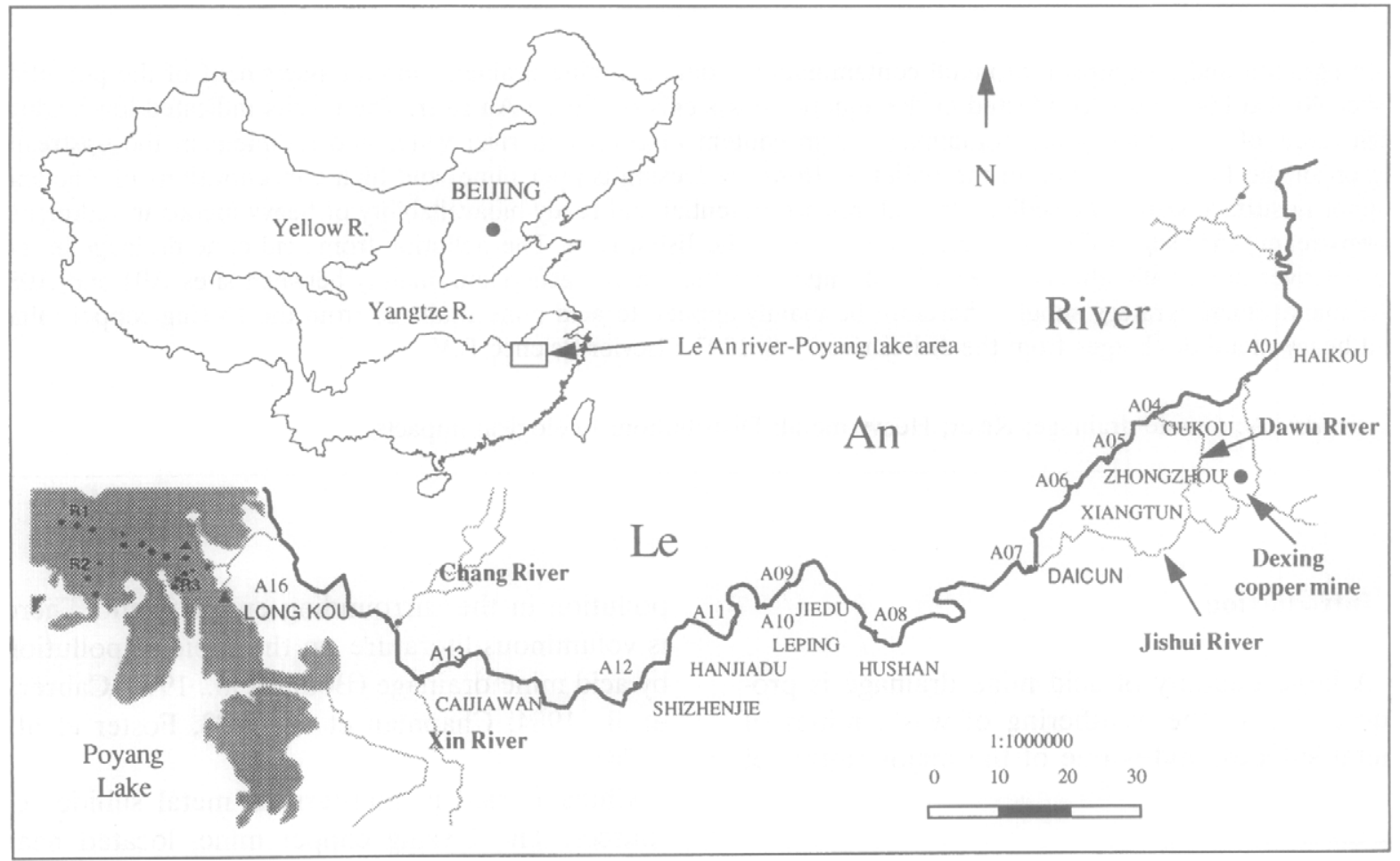

Fig. 1. Research area and sampling scheme. 
analysis and linear regression analysis, is to present a description of the spatial and temporal distribution of heavy metals in surface water and sediments and to describe the stability and bioavailability of heavy metals in sediments. An evaluation of the potential for ecological impact is also illustrated.

\section{Methods}

\subsection{Field sites, sampling and analysis}

The research area and sampling location is shown in Fig. 1. Site A01 is in upstream section of the river and is situated $20 \mathrm{~km}$ from the major mines. Site A04 is $20 \mathrm{~km}$ downstream from A01, where the acid mine drainage flows into the Le An river where is converges with the Dawu river (DWR). Site A05 is $20 \mathrm{~km}$ downstream from site A04. Site A07 is $50 \mathrm{~km}$ downstream and converges with the Jishui river. Sites A08-A13 are between 84 and $159 \mathrm{~km}$ downstream. Site A16 is $230 \mathrm{~km}$ downstream and in the delta area of the Poyang lake, the largest fresh water lake in China.

During 1987 and 1994, samples for water and sediments were collected on seven occasions in the rainy or dry season. During August 1993 and July 1994, annual hydrological and chemical monitoring at site $\mathrm{A} 08$ was carried out. The $\mathrm{pH}$ value was measured with a portable $\mathrm{pH}$ meter in situ. Surface water samples were collected with a plastic water sampler and filtered through a $0.45-\mu \mathrm{m}$ Millipore membrane in situ and acidified immediately. Conventional methods were employed for determining the physico-chemical characteristics of the water. Sediment samples were taken using a Veen grab sampler and were wet-digested after being dried at room temperature. The sediment samples when brought back to the laboratory were centrifuged at $4000 \mathrm{rev} / \mathrm{min}$ for $30 \mathrm{~min}$ to obtain the interstitial water (Backman $J 21$ freezing centrifugation). The organic carbon and sulfur in sediments were analyzed using a LECO Corporation (USA) carbon and sulfur determination model CS-225, controlled by a microprocessor. Grain size separation was carried out using nylon sieves and a settling procedure (Muller, 1967), separating the sand $(>63 \mu \mathrm{m})$, silt $(63-2 \mu \mathrm{m})$, and clay $(<2 \mu \mathrm{m})$ fractions of the sediments. Ten grams of each sample for granulometric analysis were suspended in distilled water, and dispersed by ultrasonic treatment (three times for $30 \mathrm{~s})$. The medium silt $(20-6.3 \mu \mathrm{m})$, fine silt $(6.3-2 \mu \mathrm{m})$ and clay fraction $(<2 \mu \mathrm{m})$ were separated using an 'ATTERBERG-cylinder' through repeated suspension (in distilled water) and settlement cycles. The determination of the elements $\mathrm{Cu}, \mathrm{Pb}$ and $\mathrm{Zn}$ in a standard reference sediment sample (CRM 280, COMEUR) and in a standard reference water sample (produced by the Chinese Academy of Environmental Science) was achieved by first digesting the samples in a microwave oven equipped with PFA advanced composition vessels, followed by a Perkin-Elmer Enhanced Data System 3100 GF-AAS measurement. The detection limits for $\mathrm{Cu}, \mathrm{Pb}$ and $\mathrm{Zn}$ are $0.02,0.05$ and $0.001 \mu \mathrm{g} / \mathrm{l}$, respectively.

Table 1

Physical-chemical characteristics for surface water in Le An river (in dry the season, October 1994)

\begin{tabular}{|c|c|c|c|c|c|c|c|}
\hline Sites & $\begin{array}{l}\mathrm{TC} \\
(\mathrm{mg} / \mathrm{l})\end{array}$ & $\begin{array}{l}\text { IC } \\
(\mathrm{mg} / \mathrm{l})\end{array}$ & $\begin{array}{l}\text { Conductivity } \\
(\mu \mathrm{s} / \mathrm{cm})\end{array}$ & $\begin{array}{l}\text { Turbidity } \\
\left(\mathrm{SiO}_{2}, \mathrm{mg} / \mathrm{l}\right)\end{array}$ & $\begin{array}{l}\text { Mineral } \\
(\mathrm{mg} / \mathrm{l})\end{array}$ & $\begin{array}{l}\text { Hardness } \\
\left(\mathrm{CaCO}_{3}, \mathrm{mg} / \mathrm{l}\right)\end{array}$ & $\begin{array}{l}\text { Alkalinity } \\
(\mathrm{CaO}, \mathrm{mg} / \mathrm{l})\end{array}$ \\
\hline A01 & 11.0 & 10.0 & 86.0 & 3.12 & 36.0 & 102.34 & 20.88 \\
\hline $\mathrm{A} 03$ & 9.0 & 9.0 & 131.0 & 31.47 & 176.0 & 148.39 & 17.90 \\
\hline $\mathrm{A} 04$ & 7.0 & 4.0 & 390.0 & 24.31 & 530.0 & 317.25 & 0.00 \\
\hline A05 & 11.0 & 9.0 & 164.0 & 40.12 & 172.0 & 189.33 & 20.88 \\
\hline A06 & 12.0 & 11.0 & 151.0 & 254.45 & 228.0 & 199.56 & 29.84 \\
\hline A07 & 8.0 & 8.0 & 196.0 & 23.45 & 164.0 & 143.28 & 19.09 \\
\hline A08 & 7.0 & 7.0 & 133.0 & 116.10 & 124.0 & 179.10 & 16.11 \\
\hline A13 & 10.0 & 9.0 & 121.0 & 8.47 & 118.0 & 133.04 & 24.26 \\
\hline A14 & 11.0 & 9.0 & 107.0 & 11.58 & 78.0 & 97.22 & 17.90 \\
\hline
\end{tabular}


Samples of crustacean, rotifer, algae for qualitative analysis were collected using a photoplankton net with a mesh size of $50 \mu \mathrm{m}$ from the surface water. Polyurethane foam cut into identical units (PFU- $5 \times 7 \times 8 \mathrm{~cm}$ ) was used as an artificial substrate for colonization of the protozoan communities (Xu et al., 1994). Benthonic macroinvertebrates were collected with a $0.05-\mathrm{m}^{2}$ Peterson grab at each of the sampling sites ( $\mathrm{Zhu}$ et al., 1994).

The rainy season in this area begins in April and finishes in September, in which $60-75 \%$ of annual rainfall and most of the storm floods are concentrated. From October to March, less rainfall could be observed and the flow rate in the Le An river is relatively lower (dry season).

\subsection{Data collection and statistical analyses}

All of the data for this paper were collected from the CERP database and relevant publications (Muller and Tang, 1996; Tang et al., 1994).

An ecological risk index (RI) has been used as a diagnostic tool for the potential sediment pollution of heavy metals (Lars, 1980).

Diversity indices for crustacean, rotifer, algae and protozoan communities were calculated using the Margalef diversity index (Margalef, 1957). Diversity indices for benthonic macroinvertebrates were calculated using the Shannon-Weaver diversity index (Shannon, 1949).

Principal component analysis (PCA) was used in this study to explain the interrelation of the concentrations of heavy metals and geochemical data in the sediments. The linear regression analyses were applied to evaluate both the relationship between the ecological risk index of sediments and the biological diversity index. Statisti- cal analyses were performed using the SPSS statistical software package.

\section{Results and discussion}

\subsection{Physical and chemical properties of the surface water}

The physical and chemical properties of the surface water in the dry season (October, 1994) are shown in Table 1. The contents of total carbon (TC) and inorganic carbon (IC) are 7.0-12.0 $\mathrm{mg} / 1$ and $4.0-11.0 \mathrm{mg} / \mathrm{l}$, respectively, and the lowest values are at Gukou (site A04). High electrical conductivity, total hardness and contents of mineral matter are also observed at site A04. The results show that the pollution by acid mine drainage from the Dexing Copper Mine had a significant impact on the water quality of the Le An river. Additionally, at Daicun (site A07), due to the pollution from the Jishui river, a slight variation in water quality is also observed.

Table 2 shows the average, maximum and minimum $\mathrm{pH}$ values in surface water along the Le An river during 1987 and 1994 . The $\mathrm{pH}$ values at site A04 were very low due to the acid mine drainage. Generally, at site $\mathrm{A} 05$, the $\mathrm{pH}$ values recover to normal levels due to the strong buffer capacity of the Le An river water. In the rainy season, a large quantity of acid mine drainage flowed into the Le An river, and the river water in all sampling sites was acidic $(\mathrm{pH}=3.24-6.5)$. At site $\mathrm{A} 07$, due to pollution from the Jishui river, the $\mathrm{pH}$ values were slightly lower than that of upstream sections. Additionally, at site $\mathrm{A} 12$, the $\mathrm{pH}$ values were a little lower due to the pollution of discharges of wastes from a nearby small gold mine.

Table 2

The $\mathrm{pH}$ variation of surface water in the Le An river (1987-1994)

\begin{tabular}{lcccccccccc}
\hline Sites & A01 & A04 & A05 & A06 & A07 & A08 & A09 & A11 & A12 & A13 \\
\hline Average & 7.05 & 5.18 & 6.74 & 7.08 & 6.86 & 7.01 & 7.06 & 7.08 & 6.95 & 7.09 \\
Minimum & 6.55 & 3.24 & 6.30 & 5.75 & 6.30 & 6.50 & 6.40 & 6.42 & 6.30 & 6.30 \\
Maximum & 7.65 & 7.20 & 7.30 & 7.60 & 7.20 & 7.30 & 7.32 & 7.40 & 7.35 & 7.42 \\
\hline
\end{tabular}


Table 3

Range of pollution index $(I)$ values (pollution site/water quality criteria) and frequency exceeding water quality criteria*

\begin{tabular}{|c|c|c|c|c|c|c|c|}
\hline \multirow[t]{2}{*}{ Sites } & \multirow{2}{*}{$\begin{array}{l}\text { Sampling } \\
\text { numbers }\end{array}$} & \multicolumn{2}{|l|}{ Copper } & \multicolumn{2}{|l|}{ Lead } & \multicolumn{2}{|l|}{ Zinc } \\
\hline & & Range (I) & Times & Range $(I)$ & Times & Range (I) & Times \\
\hline A01 & 7 & $1.4-2.9$ & 2 & $1.1-2.7$ & 4 & $1.1-1.3$ & 2 \\
\hline A04 & 7 & $2.9-194$ & 6 & $1.1-3.5$ & 4 & 1.4 & 1 \\
\hline A05 & 6 & $1.3-10$ & 4 & $1.4-3.1$ & 2 & $<1$ & 0 \\
\hline A06 & 5 & $1.8-19$ & 4 & $1.3-3.0$ & 3 & $<1$ & 0 \\
\hline $\mathrm{A} 07$ & 7 & $1.8-8.9$ & 4 & $1.1-2.6$ & 3 & $3.1-3.5$ & 3 \\
\hline A08 & 3 & $1.5-1.9$ & 2 & $<1$ & 0 & $<1$ & 0 \\
\hline A09 & 5 & $1.3-4.2$ & 4 & 2.6 & 1 & $<1$ & 0 \\
\hline A11 & 3 & $1.4-2.1$ & 2 & $<1$ & 0 & $<1$ & 0 \\
\hline $\mathrm{A} 12$ & 3 & $2.0-2.8$ & 2 & $<1$ & 0 & $<1$ & 0 \\
\hline A13 & 6 & $1.3-3.5$ & 4 & $1.2-3.1$ & 2 & $<1$ & 0 \\
\hline
\end{tabular}

* National water quality criteria (NS-SW-88 for type II water, GB 3838 or water quality criteria for aquatic culture, TJ-35-79); Cu, $0.01 \mathrm{mg} / \mathrm{l} ; \mathrm{Pb}, 0.05 \mathrm{mg} / \mathrm{l} ; \mathrm{Zn}, 0.1 \mathrm{mg} / \mathrm{l}$.

\subsection{Evolution of heavy metal concentrations in the surface water}

During May 1987 and October 1994, a total of seven sampling times were carried out in different seasons. Table 3 shows the range of pollution index $(I)$ values (pollution site/water quality criteria) and the frequency exceeding water quality criteria in all sampling numbers. At site A01 upstream of the river and away from the copper mine areas, the average dissolved $\mathrm{Cu}$ concentration was low. Only in June 1993 did the concentration exceed the allowable water quality criterion of the Peoples' Republic of China for surface water (GB 3838-88) and the pollution index of $\mathrm{Cu}$ was 2.9. The highest $\mathrm{Cu}$ concentration was observed at A04 $(I=3.8-194)$, while it was relatively lower at other sampling sites. In the slightly-polluted years, after site A04, the Cu concentration significantly decreased along the Le An river. In heavily-polluted seasons, from site A04 to site 13, the Cu concentration exceeded the water quality criterion, hence copper is transportcd downstrcam along the Le An river. The $\mathrm{Pb}$ concentration was higher upstream than downstream due to the pollution of acid mine drainage. The highest $\mathrm{Zn}$ concentration was observed at A07 ( $I=3.1-3.5)$.

The frequency of heavy metal concentrations for the annual hydrological and chemical moni- toring at site A08 during August 1993 and July 1994 are given in Fig. 2. The average values for $\mathrm{Cu}, \mathrm{Zn}$ and $\mathrm{Pb}$ in surface water (filtered through a $0.45-\mu \mathrm{m}$ Millipore filter) are $0.043,0.171$ and $0.025 \mathrm{mg} / \mathrm{l}$, respectively, showing that the major pollutants are $\mathrm{Cu}$ and $\mathrm{Zn}$ in surface water at site A08, which is situated $34 \mathrm{~km}$ downstream for site A07 and at the confluence of pollutants from the Le An river and the Jishui river.

\subsection{Distribution of heavy metals in suspended solids}

The Le An river is heavily polluted by acid mine drainage and contains a large amount of ore-tailing particles from Dexing copper mine. A large amount of fine-grained ore tailing and iron/aluminum oxyhydroxides constitute the majority of the suspended particles (Luan et al., 1994). Fig. 3 shows changes in the suspended solids (SS) content and distribution of metals in suspended solids in the water of the Le An river. The result shows that the content of suspended solids was relatively low in the dry season (September, 1989) compared to rainy season (June, 1993). The highest content of suspended solids, observed at site A04 and site A07 are due to the input of pollutants from the Dawu river and Jishui river, respectively. The suspended particulates accumulated a large quantity of heavy metals, mainly copper at site A04 and zinc at site A07. 

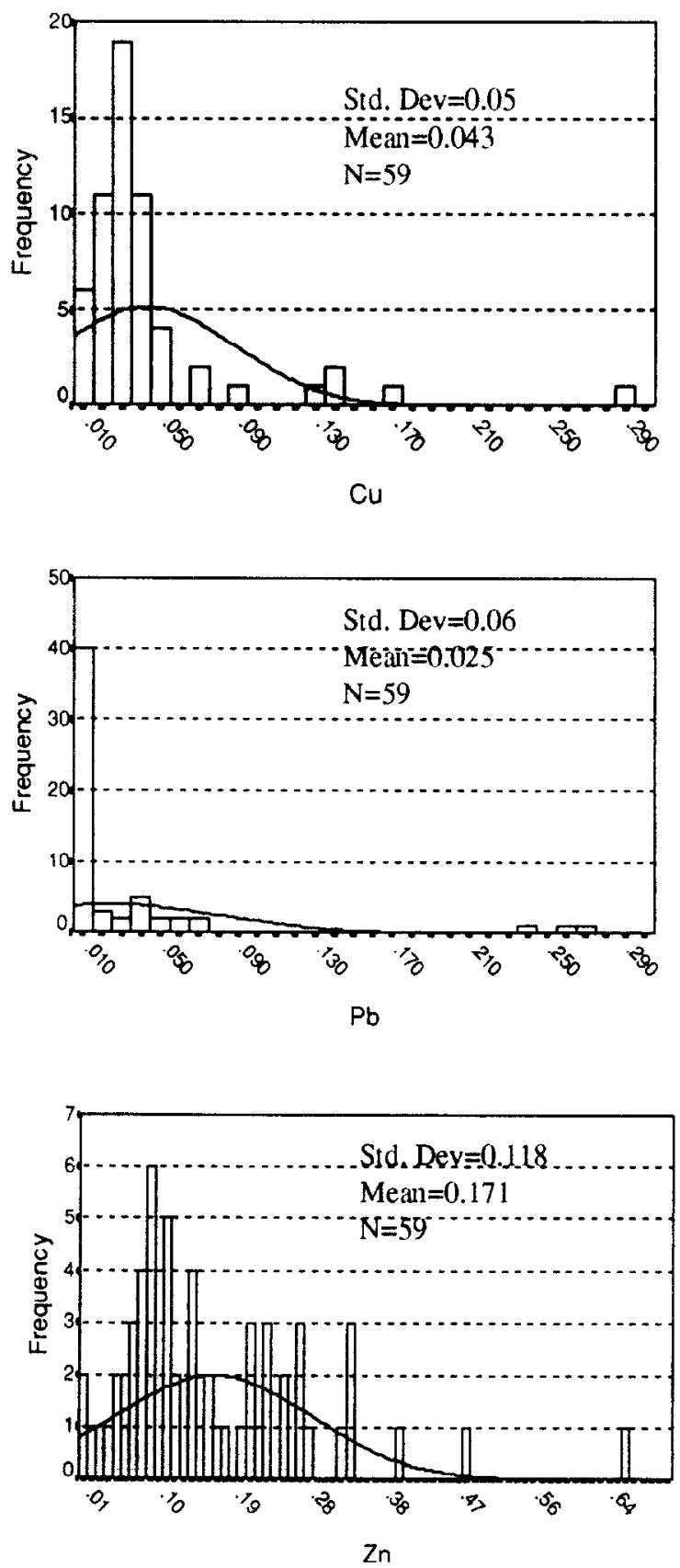

Fig. 2. Frequency of heavy metal concentration in water at Hushan $(1993,8-1994,7)$.

\subsection{Distribution of heavy metals in sediments}

The regional background values of heavy metals in the Le An river were 45, 34 and $117 \mathrm{mg} / \mathrm{kg}$ for $\mathrm{Cu}, \mathrm{Pb}$ and $\mathrm{Zn}$, respectively. Accordingly, the sediments of the Le An river were heavily polluted by heavy metals. Table 4 shows the average, minimum, maximum and medium metal concentrations in sediments sampling during 1987 and 1994. Metals that had sediment concentrations significantly above their background values were $\mathrm{Zn}, \mathrm{Pb}$ and especially $\mathrm{Cu}$. $\Lambda$ t site $\Lambda 01$, the concentrations of copper were $36(24-45) \mathrm{mg} / \mathrm{kg}$ near the background level. At site A04, due to an input of acid mine drainage, the sediments were heavily polluted. The average concentration of copper was $2878 \mathrm{mg} / \mathrm{kg}$ and the highest value reached $4100 \mathrm{mg} / \mathrm{kg}$. From site A04 to site A06, the $\mathrm{Cu}$ concentration gradually decreased due to dilution and precipitation effects, etc. At site A07, due to further pollution from Jishui river, the $\mathrm{Cu}$ concentration was relatively high. From site A08 to site $\mathrm{A} 16$, the $\mathrm{Cu}$ concentration still exceeded the regional background level. From site A01 to site $\mathrm{A} 06$, the average $\mathrm{Pb}$ concentrations were $29-44 \mathrm{mg} / \mathrm{kg}$. At site $\mathrm{A} 07$, high $\mathrm{Pb}$ concentrations (average $208 \mathrm{mg} / \mathrm{kg}$ ) were observed, especially in $1993(309.7 \mathrm{mg} / \mathrm{kg})$ and in $1994(583.8$ $\mathrm{mg} / \mathrm{kg}$ ). From site $\mathrm{A} 08$ to site $\mathrm{A} 16$, average $\mathrm{Pb}$ concentrations were $49-81 \mathrm{mg} / \mathrm{kg}$. At site A01, high $\mathrm{Zn}$ concentrations $(316 \mathrm{mg} / \mathrm{kg})$ were observed due to discharges from an active-carbon factory. The highest $\mathrm{Zn}$ concentrations were observed (average $878 \mathrm{mg} / \mathrm{kg}$, max. $1118 \mathrm{mg} / \mathrm{kg}$ ) at site A07 due to pollution from Jishui river, where there are several small copper sulfide mines, a medium sized $\mathrm{Pb}-\mathrm{Zn}$ mine and a lead smelter.

\subsection{Principal components analysis of sediment properties}

The principal component analyses for the concentrations of iron, manganese, phosphorus, copper, lead, zinc, cadmium, chromium, nickel and cobalt, as well as the proportion of carbon, sulfur and particles of various grain sizes (sand: $>63$ $\mu \mathrm{m}$; silt: 2-6.3 $\mu \mathrm{m}, 6.3-20 \mu \mathrm{m},<20 \mu \mathrm{m}, 20-63$ $\mu \mathrm{m}$; and clay: $<2 \mu \mathrm{m}$ ) were conducted. A total of four significant principal components (PC) were extracted from these data. PC 1 accounts for $37.1 \%$ of the total variance. PC 2, PC 3 and PC 4 explained $25.4 \%, 16.9 \%$ and $5.9 \%$ of the total variance, respectively. Thus, $85.2 \%$ of the total 


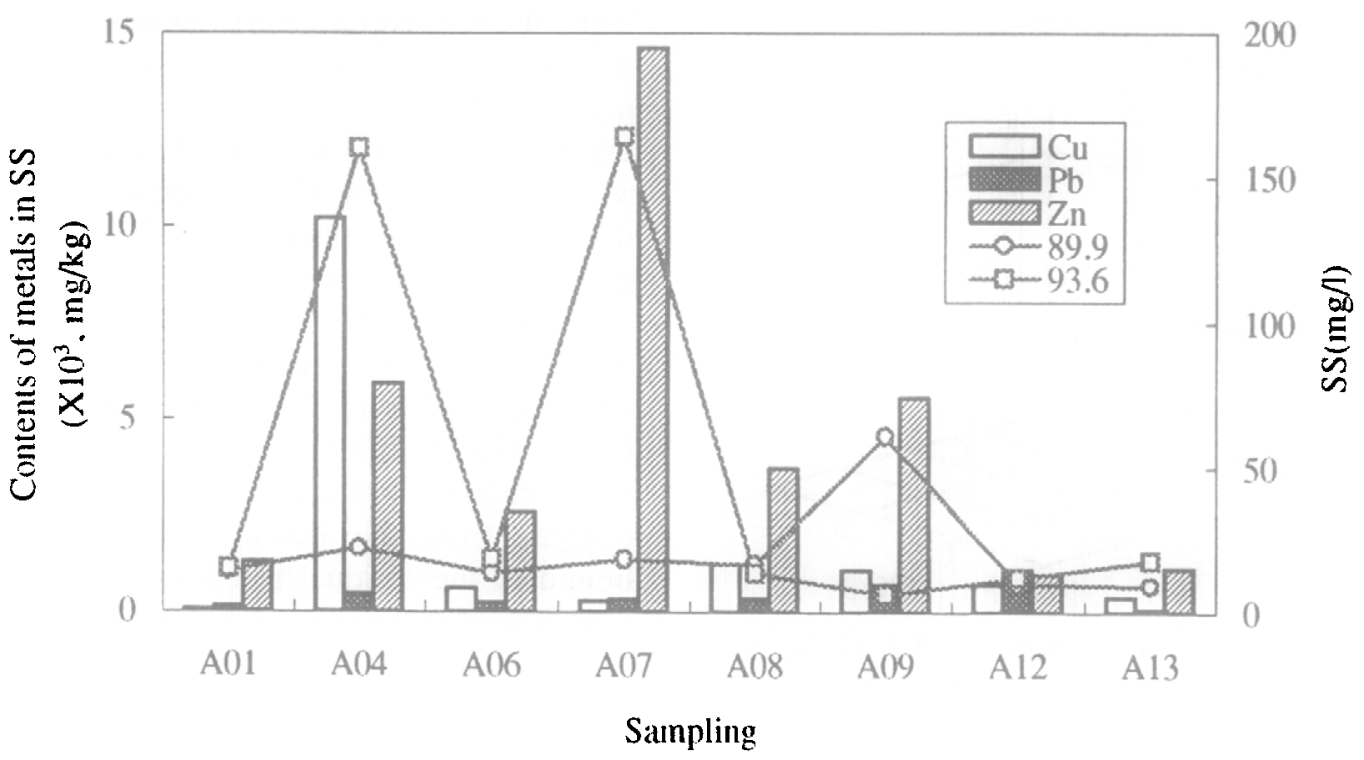

Fig. 3. Contents of suspended solids and distribution of $\mathrm{Cu}, \mathrm{Pb}$ and $\mathrm{Zn}$ in the suspended solids in the Le An river (1989,9: dry season; 1993,6: rainy season).

information could be explained by these four factors. The ordination model is presented in Fig. 4. PC 1 is the weight sum of six main parameters for particles of various grain sizes; PC 2 represents the concentrations of copper, sulfur, iron and $\mathrm{P}_{2} \mathrm{O}_{5}$. Since principal components are orthog- onal, the processes governing PC 2 are independent of PC 1. Hence, the information contained in PC 2 is more representative of pollutants from acid mine drainage. PC 3 represents the following factors: lcad, zinc, cadmium and manganese. The carbon content is represented by PC 4 .

Table 4

Distribution of $\mathrm{Cu}, \mathrm{Pb}$ and $\mathrm{Zn}$ in sediments in Le An river (1987-1994)

\begin{tabular}{|c|c|c|c|c|c|c|c|c|c|c|c|c|c|}
\hline Sites & A01 & $\mathrm{A} 04$ & A05 & A06 & $\mathrm{A} 07$ & $\mathrm{~A} 08$ & A09 & A11 & $\mathrm{A} 12$ & A13 & A14 & A15 & A16 \\
\hline \multicolumn{14}{|c|}{$\mathrm{Cu}$} \\
\hline Average & 36 & 2878 & 2173 & 1788 & 1012 & 733 & 523 & 439 & 660 & 464 & 247 & 206 & 215 \\
\hline Median & 34 & 2891 & 1790 & 1648 & 914 & 950 & 439 & 568 & 674 & 506 & 290 & 251 & 310 \\
\hline Minimum & 24 & 1405 & 1134 & 1177 & 406 & 100 & 90 & 241 & 472 & 172 & 80 & 124 & 131 \\
\hline Maximum & 45 & 4100 & 4185 & 2285 & 1906 & 1055 & 1257 & 657 & 851 & 614 & 350 & 287 & 333 \\
\hline \multicolumn{14}{|l|}{$\mathrm{Pb}$} \\
\hline Average & 44 & 42 & 44 & 29 & 208 & 94 & 68 & 77 & 79 & 75 & 67 & 49 & 81 \\
\hline Median & 35 & 33 & 43 & 33 & 179 & 103 & 74 & 68 & 67 & 79 & 72 & 59 & 82 \\
\hline Minimum & 15 & 7 & 13 & 15 & 32 & 44 & 68 & 41 & 72 & 32 & 34 & 39 & 66 \\
\hline Maximum & 95 & 100 & 121 & 38 & 584 & 150 & 116 & 141 & 126 & 113 & 112 & 98 & 96 \\
\hline \multicolumn{14}{|l|}{$\mathrm{Zn}$} \\
\hline Average & 316 & 221 & 201 & 202 & 878 & 664 & 451 & 830 & 624 & 505 & 304 & 353 & 226 \\
\hline Median & 245 & 65 & 161 & 157 & 1006 & 600 & 449 & 608 & 616 & 521 & 298 & 314 & 253 \\
\hline Mininum & 170 & 62 & 66 & 93 & 113 & 391 & 177 & 190 & 502 & 164 & 125 & 179 & 59 \\
\hline Maxinum & 1040 & 1497 & 532 & 568 & 1501 & 1159 & 787 & 1618 & 814 & 670 & 692 & 548 & 402 \\
\hline
\end{tabular}

Units, $\mathrm{mg} / \mathrm{kg}$. 


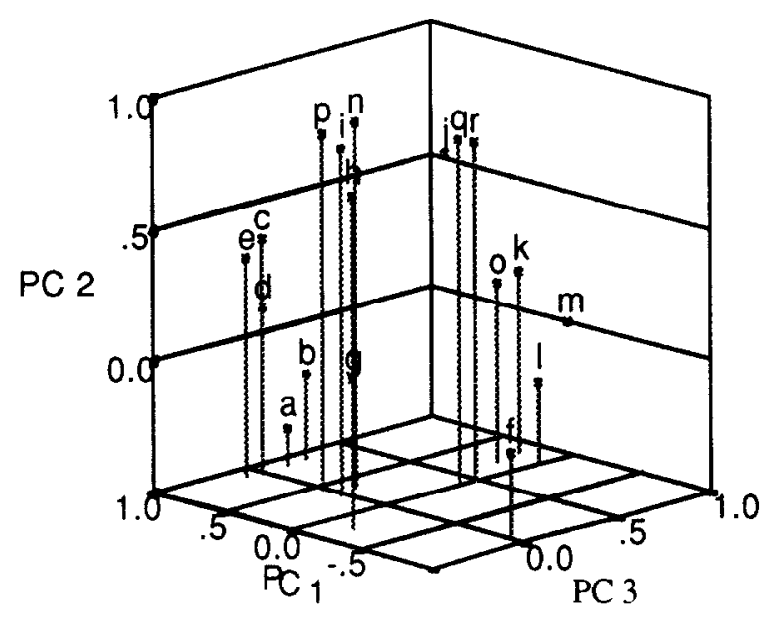

Fig. 4. Sediment PCA ordination model: PC1, 37.1\%; PC2, 25.4\%; PC3, 16.9\%. (a, <2 $\mu \mathrm{m}$; b, 2-6.3 $\mu \mathrm{m} ; \mathrm{c}, 6.3-20 \mu \mathrm{m}$; d, $<20 \mu \mathrm{m}$; e, silt; f, > $63 \mu \mathrm{m} ; \mathrm{g}, \mathrm{C}(\%) ; \mathrm{h}, \mathrm{S}(\%) ; \mathrm{i}, \mathrm{P}_{2} \mathrm{O}_{5} ; \mathrm{j}, \mathrm{Cu} ; \mathrm{k}$, $\mathrm{Zn} ; \mathrm{l}, \mathrm{Pb} ; \mathrm{m}, \mathrm{Cd} ; \mathrm{n}, \mathrm{Fe}$; o, Mn; p, Cr; q, Ni; r, Co).

\subsection{Stabilization and bioavailability of heavy metals in sediments}

Fig. 5 shows the concentration of heavy metals in interstitial water. The results indicate that the major pollutants are copper in the interstitial water of sediments along the Le An river and a high zinc concentration was observed at site $\mathrm{A} 12$ due to pollution by wastes from a nearby gold mine. High contents of sulphate, hydroxide, iron, manganese and a low content of organic matter were generated by the pollution of acid mine drainage in sediments upstream in the river, especially at site A04 (Dai et al., 1994).

According to the speciation analysis (Mao, 1996), studied by sequential selective chemical extraction following the method of Tessier et al. (1979), the background (site A01) copper was in the carbonate-binding fraction; the copper discharged from the Dexing copper mine mainly bound to the residual fractions; the copper content downstream (after site A07) was mainly in the pyrite/organic binding fraction and the residual fractions. The copper content of the sediment is relatively more stable at site A01 and upstream (site A04-A06) rather than downstream, especially at site A07 (Mao, 1996). The highest contents of heavy metals in water extracts (Wang and Tang, 1994) and in the interstitial water of sediments were also at site A07. Additionally, the potential release of sediment-bound heavy metals were higher at site $\mathrm{A} 07$ than in the upstream site A05 (Wen and Herbert, 1997a). The measure-

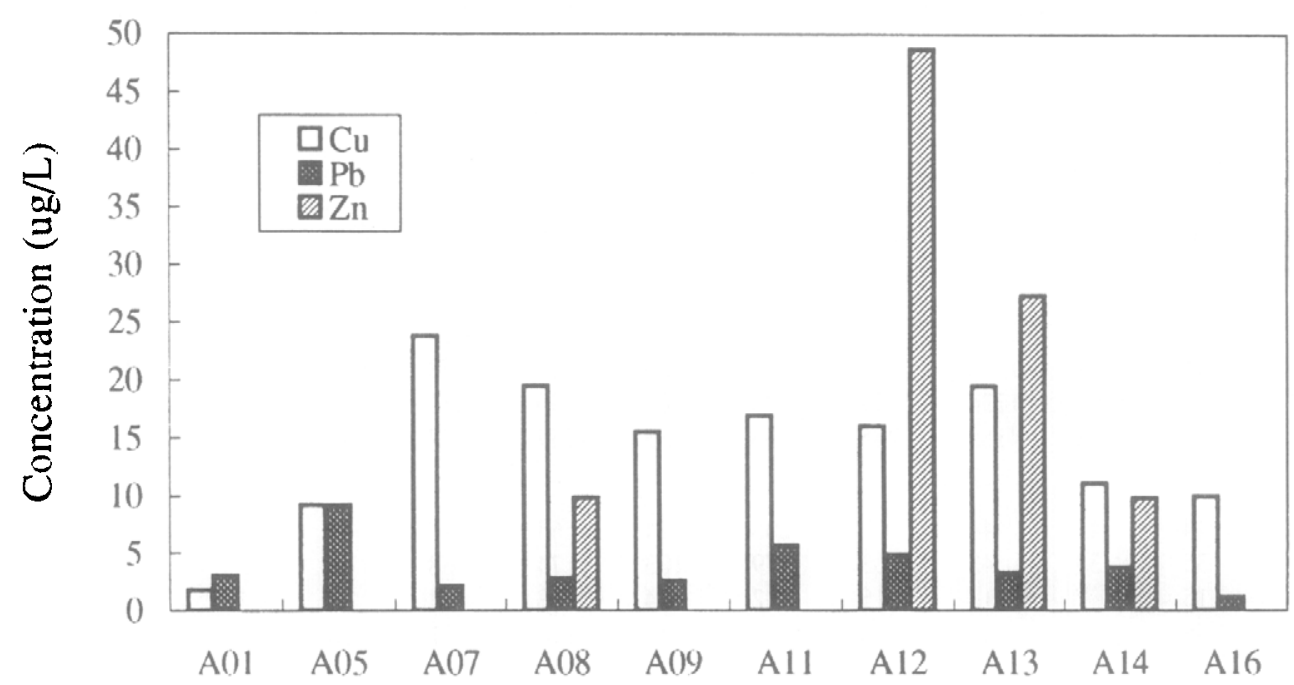

\section{Sampling sites}

Fig. 5. Metal content of interstitial water in the sediments of the Le An river. 
ment of acid volatile sulfide (AVS) and simultaneously extracted metals (SEM) showed that the major binding component for metals were most likely to be iron and magnesium oxide at site A07 (Wen and Herbert, 1997b). The result of the toxicity bioassay proved that the interstitial water and extracts of sediments at site A07 exhibited strong toxicity than that of upstream waters. Hence the sediments in the downstream (after site A07) sector represent a strong risk for pollution and are readily bioavailable.

\subsection{Prediction of the potential for ecological effects}

A total of 123 species of algae, 32 species of crustacean, 19 species of rotifer, 58 species of protozoa and 26 species of benthos were collected at six sampling sites along the Le An river and the diversity indices were calculated ( $\mathrm{Xu}$ et al., 1994; Zhu et al., 1994). The ecological risk indices of sediments were calculated for assessing the multiple metal pollution (He et al., 1997). The variation of flow rate, water depth and temperature along the Le An river was small ( $\mathrm{Lin}$ and $\mathrm{Li}$,
1994). Xu et al. (1994) and Zhu et al. (1994) confirmed that the main factors of impact on aquatic ecosystems were heavy metals and $\mathrm{pH}$, and the impact on the diversity index was not related to other environmental conditions. In this study, we conducted the linear regression analysis between the diversity index and risk index (RI). The results (Fig. 6) show that a notable correlation exists between the diversity index for algae, zooplankton (crustacean and rotifer), protozoa and benthonic macroinvertebrae and the ecological risk index (RI). The coefficient of determination for the relationship between diversity index and risk index were $0.9499,0.8591,0.8976$ and 0.9176 for algae, zooplankton, benthos and protozoa, respectively. According to the regression equations, on the basis of the RI values of sediments, we calculated the diversity index and the average ratio of the diversity index (pollution site/control site) for algae, zooplankton, benthos and protozoa at all sampling sites. The ecological effect of sediments for the Le An river were predicted, based on the values of the average ratio of the diversity index (pollution site/control
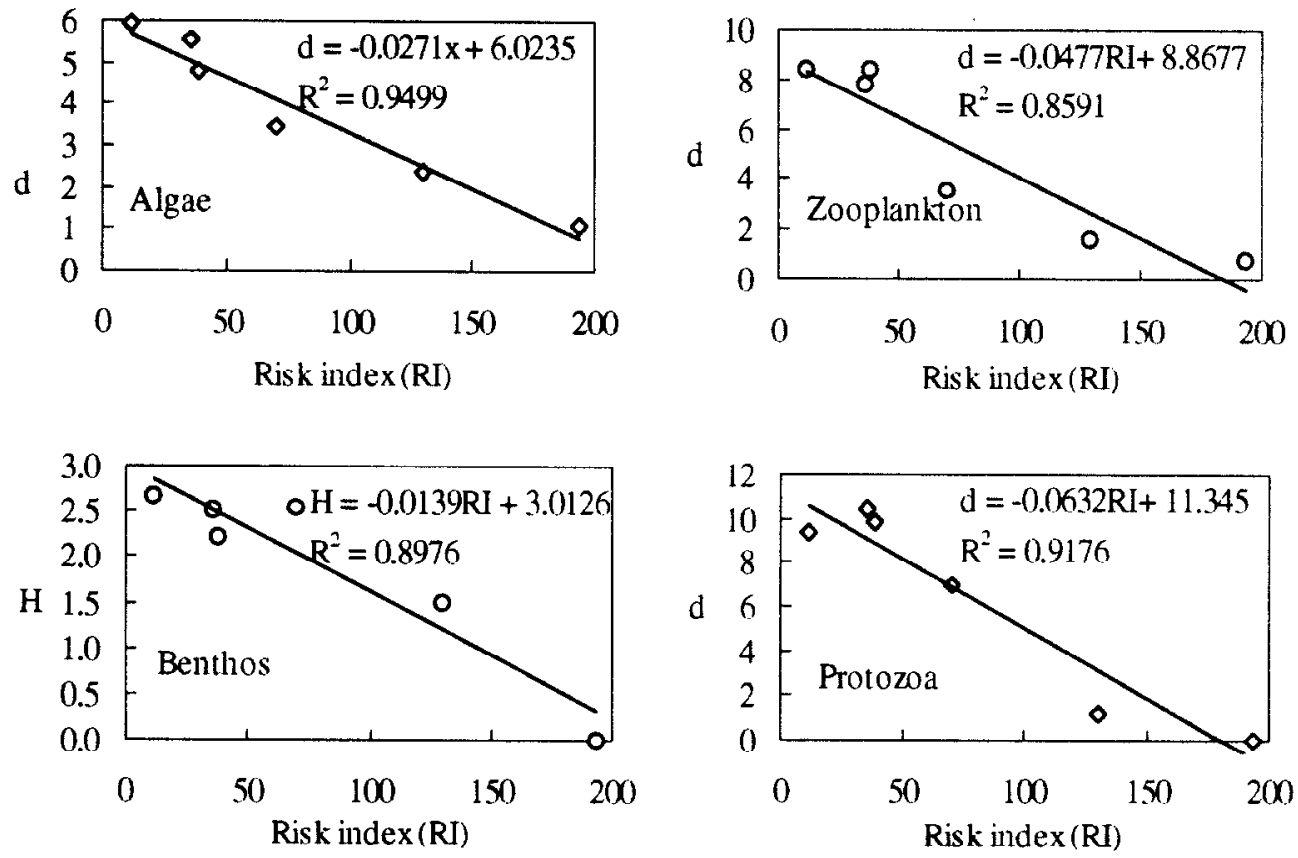

Fig. 6. Linear regression analysis of diversity index vs. risk index (RI) of sediments. 


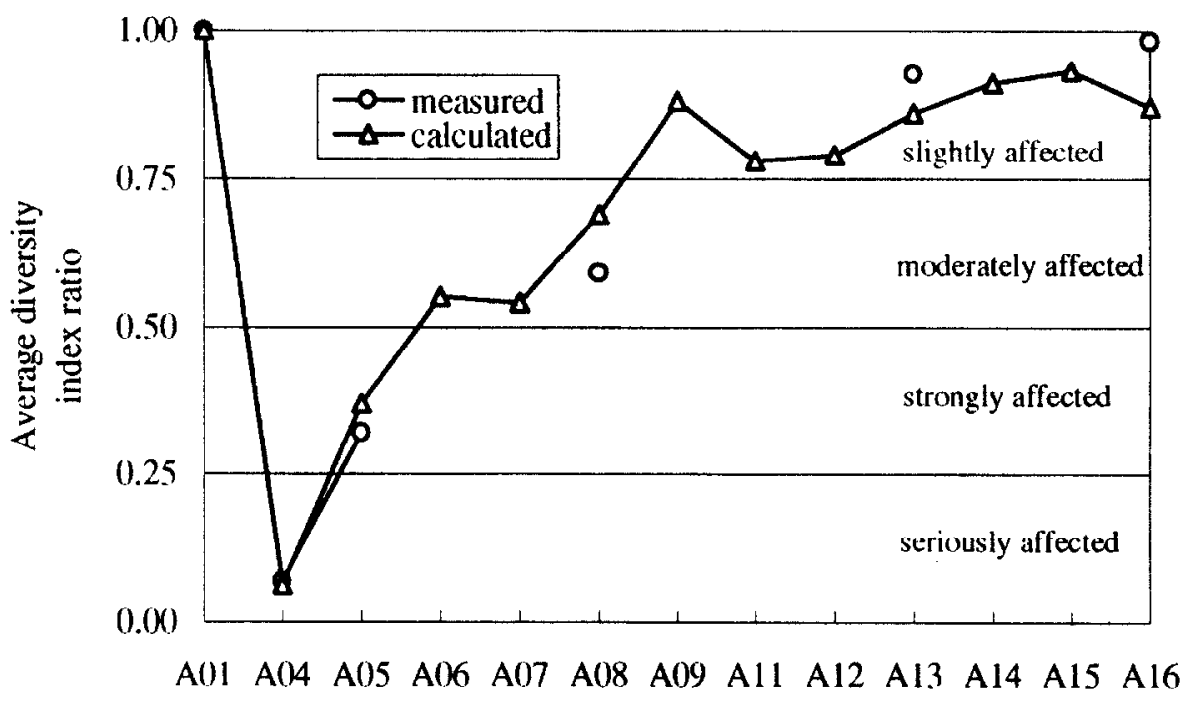

Sampling sites

Fig. 7. The predicting diversity index ratio (pollution site/control site) and the ecological effects.

site), using the hierarchical model ( $\mathrm{He}$ et al., 1997): class I: 1.0 , no-effect; class II: $0.75-1.0$, slightly affected; class III: $0.5-0.75$, moderately affected; class IV: $0.25-0.5$, strongly affected; class $\mathrm{V}:<0.25$, seriously affected. The results (Fig. 7) show that the aquatic ecosystem was seriously affected at site A04, strongly affected at site A05, moderately affected from site A06 to site A08, and slightly affected after site A08.

\section{Conclusions}

By integration and comparison of several years' data, the results clearly show that the discharges from Dexing copper mine and mines along Jishui river has resulted in a significant increase in the concentration of copper, zinc and lead in water and sediments along the Le An river. At site A04, the low acidity, high contents of suspended solids and high concentration of copper in river water and sediment are the main pollution problems. At site A07, high concentrations of zinc and copper in surface water and sediment are observed. At other sites downstream, high concentrations of copper and zinc are observed. The spatial variation of geochemical data in sediments could bc explained using PCA analysis. The ecological ef- fects of acid mine drainage can be predicted based on the risk index (RI) of sediments. The river water and sediment pollution in the Le An river have strongly affected the aquatic ecosystem, mainly between sites A04 and A08. The management priority should be addressed mainly to acid mine drainage from Dexing copper mine and heavy metals discharges from Jishui river.

\section{Acknowledgements}

The author would like to thank the participants in the project, who also provided the data for this paper. We cannot list their names because more than 20 scientists contributed to the work (including scientists from Germany). Special thanks are due to German BMBF and Chinese CAS for providing funding support and to $\mathrm{Dr}$ Thomas Schaaf in Paris office of UNESCO and Prof. Zhao Xiangyin from Chinese MAB for coordinating the project.

\section{References}

Boult S, Collins DN, White KN, Curtis CD. Metal transport in a stream polluted by acid mine drainage-The Afon Goch, Anglesey, UK. Environ Poll 1994;84:279-284. 
Cabrera F, Toca CG, Diaz E, Arambarri PDE. Acid minewater and agricultural pollution in a river skirting the Donana National Park (Guadiamar river, South West Spain). Water Res 1984;18:1469--1482.

Chapman BM, Jones DR, Jung RF. Processes controlling metal ion attention in acid mine drainage streams. Geochem Cosmochim Acta 1983;47:1957-1973.

Dai Z, Starke R, Kleeberg R, Wang X, Liu Y. Physico-chemical properties of Le An river sediments. China Environ Sci 1994;5:129-134.

Du $\mathbf{Q}$, Wen X, Tang $\mathbf{H}$. Surface complexion model for the adsorption of heavy metals on the river sediment nearby Poyang Lake. China Environ Sci 1994;5:140-148.

Foster P, Hunt TE, Morris AW. Metals in acid mine stream and estuary. Sci Tot Environ 1978;9:75-86.

He M, Wang Z, Tang $\mathrm{H}$. The chemical, toxicological and ecological studies in assessing the heavy metal pollution in Le An river, China. Water Res 1997:in press.

Lars $H$. An ecological risk index for aquatic pollution control: A sedimentological approach. Wat Res 1980;14:975-1001.

Lin $\mathrm{Y}, \mathrm{Li}$ Q. Study on the heavy metal speciation modeling in aquatic system of Le An river. J Environ Sci (China) 1992;4:100-108.

Lin $\mathrm{Y}, \mathrm{Li} \mathrm{Q}$. The present change of heavy metal pollution in Le An river-Poyang Lake. China Environ Sci 1994;5:110-115.

Lin Y, Li Q, Zou G, Shi S. Impacts of acid mine drainage on water quality of Le An river and Poyang Lake area. J Environ Sci (China) 1992;4:4-13.

Luan Z, Klute R, Hahn H, Tang $H$. The stability and aggregation of fine-grained ore tailing, hydrous $\mathrm{Fe} / \mathrm{Al}$ oxides and their binary mixtures in natural water. China Environ Sci 1994;5:149-158.

Mao M. Speciation of metals in sediments along the Le An river. in the Final report of the Co-operative Ecological Research Project (CERP). Published in 1996 by the United Nations Educational, Scientific and Cultural Organization, 1996:1-57.

Mao M, Liu Z, Dong H. Distribution and speciation of metals in sediments along Le An river. J Environ Sci (China) 1992:4:72-81.

Margalef R. Information theory in ecology . Mem. real acal. 3rd ser. Barcelona 1957;32:374-449.

Muller G. Methods in sedimentary petrology Part one. Schweizerbart Stuttgart 1967:283.
Muller G, Tang H. Ecological effects of heavy-metal pollution in the Dexing Copper Mine region in Jiang Xi Province, China. Final report of the Co-operative Ecological Research Project (CERP). Published in 1996 by the United Nations Educational, Scientific and Cultural Organization, 1996.

Ramezani N. Heavy-metal concentrations in sediment from the Le An river to Poyang lake. Final report of the Co-operative Ecological Research Project (CERP). Published in 1996 by the United Nations Educational, Scientific and Cultural Organization, 1996.

Shannon C. The Mathematical Theory of Communication. Urbana: Univ. Illinois Press, 1949:49-73.

Tang H, Wang Z, Liu J, Muller G. Ecological impacts of heavy metal pollution from Dexing Copper Mine to Poyang Lake-Recent research progress in CERP-continual phase. China Environ Sci 1994;5:97-101.

Tessier A, Campbell PGC, Bisson M. Sequential extraction procedure for the speciation of particulate trace metals. Anal Chem 1979;51:844.

Wang $\mathrm{H}$, Tang $\mathrm{H}$. Toxic effects of the polluted sediments in Le An river on Hydrobios. China Environ Sci 1994:5:165-168.

Wang Z, Ma M, Du Q, Wen X. Toxic assessment by Photobacterium phosphoreum. China Environ Sci 1994; 5:159-164

Wen X, Herbert E.A. The acid and base properties of Le An river sediment and their influence on the release of heavy metals contained in sediment samples. Environ Chem (in Chinese), 1997a:in press.

Wen X, Herbert E.A. Acid-volatile-sulfide(AVS) in Le An river sediment and the effect of oxygen on the release of heavy metals in the sediment. Environ Sci (in Chinese), 1997b:in press.

Xu M, Gao Y, Ma M, Wang Z. The relationship between the changes of plankton community structure and the metal pollution in Le An river. China Environ Sci 1994;5:172-176.

Yahya A, Song Y. Distributions of heavy metals in sediments and pore waters of $\mathrm{Le} A \mathrm{~A}$ river at Caijiawan. China Environ Sci 1994;5:105-109.

Zhu J, Ren S, Lin Z, Lin Y. Preliminary study on the benthic macroinvertebrate community relating to the metal pollution in Le An river. China Environ Sci 1994;5:177-181. 